\title{
Applicability of a vegetation indices-based method to map bark beetle outbreaks in the High Tatra Mountains
}

\author{
M. Havašová, T. Bucha, J. Ferenčík, R. Jakuš
}

Havašová M., Bucha T., Ferenčík J., Jakuš R., 2015. Applicability of a vegetation indices-based method to map bark beetle outbreaks in the High Tatra Mountains. Ann. For. Res. 58(2): 295-310.

Abstract. Automatic identification of forest patches disturbed by the spruce bark beetle Ips typographus L. is crucial to reveal the rules of following bark beetle outbreaks on the landscape scale. Landsat imagery provides free resources to outline past and present gradations of bark beetle outbreaks (BBOs). The objective of this study is to identify the most sensitive vegetation index through different method of vegetation index differencing to identify past and actual bark beetle outbreaks. Six Landsat Thematic Mapper (TM) images, from 2005-2009 and 2011, were converted into selected vegetation indices (VIs) sensitive to conifer tree health in a Norway spruce-dominated forest in the High Tatra Mountains. The Vegetation Condition Index (VCI), Moisture Stress Index (MSI), Normalised Difference Moisture Index (NDMI), Normalised Difference Vegetation Index (NDVI), Disturbance Index (DI) and Changed Disturbance Index (DI') were calculated separately for every year, and the methodology of vegetation index differencing was applied to multiple two-year time periods (2005-2006, 2006-2007, 2007-2008, 2008-2009 and 2010-2011), thus producing the Changed Vegetation Index $(\Delta \mathrm{VI})$. A set of thresholds was established on $\Delta \mathrm{VI}$ to classify disturbed and undisturbed forest due to BBOs; the sensitivity of different VIs to identify BBO was equally evaluated. The highest accuracies of classifications were reached in 2007 and 2011 (kappa index of agreement $>70 \%$ and $>40 \%$, respectively), which were characterised by an epidemic phase of a BBO. All selected VIs were highly sensitive to BBOs, except for NDVI. The stable threshold value for change detection is not widely applicable to detect past forest disturbances caused by bark beetles, however. Finally, for further research of the epidemic phases of BBOs, we recommend the utilisation of the vegetation indices VCI, MSI and NDMI to detect BBOs because of their simplicity and easy interpretability. Keywords Ips typographus L., remote sensing, change detection, vegetation index differencing.

Authors. Mária Havašová (maria.havasova@gmail.com) - Institute of Forest Ecology, Slovak Academy of Sciences, Ludovíta Štúra 2, 96053 Zvolen, Slovakia; Tomáš Bucha - National Forest Centre, T. G. Masaryka 22, 96092 Zvolen, Slovakia; Ján Ferenčík - Research station Tatra national park, 05960 Tatranská 
Lomnica, Slovakia; Rastislav Jakuš - Institute of Forest Ecology, Slovak Academy of Sciences, Ludovíta Štúra 2, 96053 Zvolen, Slovakia, Department of Forest Protection and Entomology, Faculty of Forestry and Wood Sciences, Czech University of Life Sciences, Kamýcká 1176, 16521 Praha 6 - Suchdol, Czech Republic.

Manuscript received February 13, 2015; revised April 23, 2015; accepted April 29, 2015; online first May 18, 2015.

\section{Introduction}

Bark beetles, which cause tree mortality, are an important means of disturbance in spruce $(P i$ cea abies [L.] Karst.) forests in Central Europe (Schelhaas et al. 2003, Svoboda et al. 2010, Svoboda et al. 2012). After an extensive gale disaster in 2004, there was a large bark beetle outbreak in the Tatra Mountains (Nikolov et al. 2014). The outbreak was eruptive in southernfacing slopes of the central part of the mountains. Almost all mature spruce stands were damaged. Bark beetle outbreaks (BBOs) are caused mainly by Ips typographus L. Although aerial photography is widely used to monitor BBOs, this approach is limited by budget constraints and by the timing of actual outbreaks. Landsat imagery provides broad potential, not only for the actual mapping of BBOs, but equally for their historical mapping. The Landsat data archive (available at http://glovis.usgs. gov/), which dates to the 1970 s, is currently free to the public (Wulder \& Coops 2013). It is a key resource for monitoring and identifying changes in forests (Vogelmann et al. 2009), including those caused by disturbances (Zhu et al. 2012, Wulder \& Coops 2013) such as bark beetle infestations (Wulder et al. 2005).

BBOs can be monitored by utilising single Landsat imagery acquired during the vegetation period, mostly in the autumn (Kennedy et al. 2010). The application of a time series of Landsat images reveals not only information about the changed area, but also gradual ecosystem changes (Vogelmann et al. 2012). Landsat data of high resolution $(30 \times 30 \mathrm{~m})$, via its temporal frequency, provide a rich source for monitoring BBOs, not only in years of actual outbreaks, but also to assess previous outbreaks and to evaluate stand vigour in order to predict bark beetle-induced mortality (Coops et al. 2009).

There is no single, generally applicable detection technique for monitoring changes to forests, as different algorithms need to be compared to find the best technique for a specific purpose (Lu et al. 2004). The classification of Landsat imagery is performed using singledate classifications, or by applying multiple years to forest classifications. In forest conditions, the reflectance of one Landsat pixel of 30 $\times 30 \mathrm{~m}$ resolution is formed by the reflectance of all elements occurring in that pixel, including green and dead trees, shadows, understory vegetation, rocks and other elements.

While this amalgamation of elements could make applications of single-date classification of BBOs difficult (Lefsky \& Cohen 2003), a multi-date approach that focusses on relative distances in the spectral response between two images' dates can detect subtle changes, such as damaged trees; in other words, if the first image date was selected at a time prior to the infestation, and a later date was selected when both the infestation and the number of infested trees had increased (Wulder et al. 2006). The other advantage is that intermediate steps in single-date forest mapping are not required; the potential errors associated with singledate classifications are thus eliminated (Bucha $\&$ Stibig 2008). The multi-date approach can be applied to the identification of bark beetle damage in long time series (Goodwin et al. 2008, Meddens et al. 2013) or to the utilisation of a few Landsat images to identify changes from time $T$ to time $T+n$, without specifying a 
time interval. Landsat imagery has been successfully used in forest cover classification and disturbance mapping (overall accuracy of 73\% and $86 \%$, respectively) over the whole Carpathian range within five-year intervals from 1985 to 2010 (Griffiths et al. 2014).

Jakuš et al. (2003) conducted BBO identification in the High Tatra Mountains in 2003 using Landsat imagery by the Vegetation Index (VI) method. They identified BBOs as 'changed' at different levels of standard deviations (SDs). The best index for BBO identification was the Vegetation Condition Index (Jakubauskas \& Price 1997) at the level of the mean -1.75 - SD. Jakuš and colleagues only visually assessed the accuracy of the classification procedure, however.

In this paper, we follow the principles of the preliminary study of Jakuš et al. (2003) in $\mathrm{BBO}$ detection using VI differencing. The first aim of the study was to identify the best VIs, derived by VI differencing to characterise BBOs for multiple two-year time periods. The classified Changed VI $(\Delta \mathrm{VI})$ was compared to a reference set of aerial infrared photography.
The most appropriate VI among the six selected VIs was determined using kappa statistics and Receiver Operator Characteristics (ROC) curves. The second aim of the study was to evaluate if this threshold value remained unchanged from one time period to another, and, accordingly, to assess whether this threshold value can be applicable for mapping historical BBOs without using a reference dataset such as infrared aerial photography.

\section{Material and methods}

\section{Study area}

The study area (Figure 1) is situated on the southern-facing slopes of the highest range of the Carpathian Mountains - the High Tatra Mountains, in Slovakia. The study area is localised in the forest compartments of Tatranská Lomnica and Kežmarské Žl'aby $\left(49^{\circ} 11^{\prime} 15.95^{\prime \prime} \mathrm{N}, 20^{\circ} 14^{\prime} 42.63\right.$ 'E), with a total area of 3,800 ha. The forested area ranges from 1,100 to 1,700 metres a.s.l. Planted

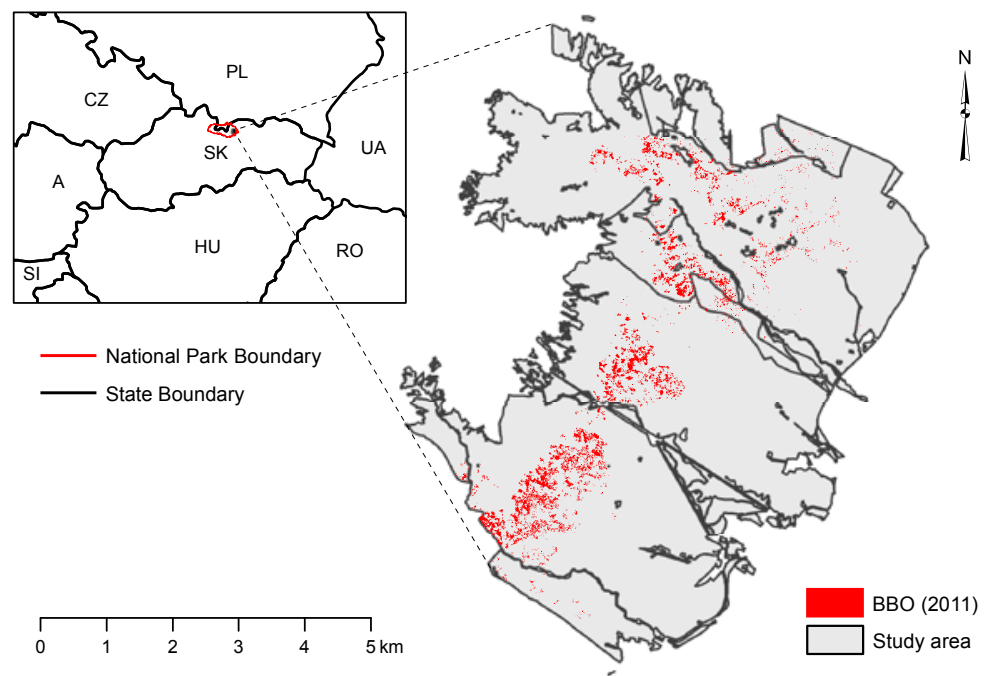

Figure 1 Study area on the southern slopes of the High Tatra Mountains, Slovakia. A bark beetle outbreak from 2011 (BBO, red) was mapped by visual interpretation of aerial photography 
spruce monocultures at areas below 1,100 m a.s.l. were excluded to eliminate the potential influences of other disturbance agents, such as fungal diseases (Armillaria spp.). The selected study area of Tatra National Park was left in a non-intervention zone following a windstorm in November 2004. Forest stands consist of more than 50\% Norway spruce (Picea abies L. Karst.). Dwarf mountain pine (Pinus mugo L.) stands are mainly present at higher elevations. Other coniferous trees are represented by European larch (Larix decidua Mill., 5\%), Scots pine (Pinus sylvestris Roth, 6\%) and silver fir (Abies alba Mill., 0.5\%). The share of deciduous tree species is about $30 \%$; the most abundant species are silver birch (Betula pendula Roth.) and mountain ash (Sorbus aucuparia L.) (available at http://gis.nlcsk.org/lgis/). The studied forest stands were managed by standard forestry methods before the creation of the national park in 1949. Later, 'close-to-nature' forestry methods were applied. These forest stands could be characterised as being near-tonatural sites.

Annual average precipitation of the study area is $1,600 \mathrm{~mm}$, and the annual temperatures range from a mean minimum temperature of $-4.9^{\circ} \mathrm{C}$ in January to a mean maximum temperature of $8^{\circ} \mathrm{C}$ in July (Lapin et al. 2002).

The selected area was greatly affected by the windstorm in November 2004, after which a
BBO began to develop (Nikolov et al. 2014). In 2005, the incipient epidemic phase started, followed by an epidemic phase in 2007 . A postepidemic phase appeared after 2011. Because of the large-scale development of BBOs in the last few years, terrestrial methods of bark beetle monitoring are not more appropriate.

\section{Satellite data pre-processing}

For the purposes of this study, we used six mosaics of Landsat TM and ETM+ imagery (Table 1). Satellite scenes were downloaded from a USGS archive (http://glovis.usgs. gov/): we used orthorectified-product L1T Terrain Corrected images, in UTM map projection in the WGS 84 system. All scenes were transformed into an S-JTSK coordinate system (Krovak projection, Bessel ellipsoid 1841) using a transformation module in ArcGIS 10.2.1. The geometric root mean square (RMS) error at Landsat $5 \mathrm{TM}$ and Landsat 7 ETM+ was around 4-5 $\mathrm{m}$ reported for the whole scene. Geometric precision correction is expected to be lower with RMSE, however: around 0.5 pixel in the mountain region of the High Tatra Mountains. Landsat mosaics for single years were created from multiple images from June to September to ensure that there was no cloud cover or cloud shadows and, if possible, no strips in the Landsat 7 ETM images. Landsat

Table 1 Mosaics of Landsat images. The image from the date in bold was used as the master image

\begin{tabular}{|c|c|}
\hline $\begin{array}{l}\text { Landsat } \\
\text { scene } \\
\text { (Path/Row) }\end{array}$ & Acquisition date (Landsat sensor) \\
\hline $188 / 26$ & 19.VII.2006 (L5 TM) + 11.VII. 2006 (L7 ETM+) \\
\hline $187-188 / 26$ & $\begin{array}{l}\text { 22.VII.2007 (L5 TM) + 23.VIII.2007 (L5 TM) + 17. IX. } 2007 \text { (L5 TM)+ 31.VIII } 2007 \text { (L5 } \\
\text { TM) + 25.IX. } 2007 \text { (L7 ETM+) }\end{array}$ \\
\hline $187-188 / 26$ & 2.IX.2008 (L7 ETM+) + 26.VIII.2008 + 13.X.2008 (L7 ETM+) + 29.V.2008 (L7 ETM+) \\
\hline $187-188 / 26$ & 21.VIII.2009 (L5 TM) + 20.VIII.2009 L7 ETM+) \\
\hline $188 / 26$ & 12.VI.2010 (L5 TM) + 23.VIII.2010 (L7 ETM+) \\
\hline $187-188 / 26$ & $\begin{array}{l}\text { 27.VIII.2011 (L5 TM) + 26.VIII. } 2011 \text { (L7 ETM+) + 3.IX.2011 (L5 TM) + 11.VIII.2011 } \\
\text { (L5 TM) }\end{array}$ \\
\hline
\end{tabular}


images are composed of seven (L5 TM) and eight bands (L7 ETM+); in our study, we used only six bands in $30 \times 30 \mathrm{~m}$ pixel size (bands $1-5$ and 7 without band 6 as thermal infrared) with digital numbers (DNs) ranging from 0 255.

Before creating a mosaic, it was necessary to eliminate differences in spectral reflectance caused especially by different atmospheric conditions at the time of scanning and different scanning geometry. We used radiometric normalisation using image regression. This method simply involves relating each pixel of the subject image with that in the reference image band by band to produce a linear equation through a least-squares regression (Jensen 1986, Singh 1989). The regression technique accounts for the differences in the mean and variance between radiance values for different dates. In our approach the method uses only forest pixels in the reference-subject image pair. Olsson (1993) proved that regression functions computed only from forest pixels yielded higher coefficients of determination than functions computed from all image pixels, or from dark and bright areas only. The forest pixels could be considered to be pseudoinvariant features, i.e. objects with nearly invariant reflectivity from one image scene to another during the vegetation season (Xiaojun \& Lo 2000). A mask of the forest was taken, as per the work of Bucha (1999). Simple thresholds were used to eliminate new clear-cuts and calamitous areas from the mask.

Previous works have shown that ratio-based indices and some linear combinations of Landsat bands are not affected by the topography of the terrain. Therefore it was not necessary to carry out topographic normalisation of images to eliminate varying shadowing. All Landsat images were cropped to the final study area. The scheme for processing Landsat images is shown in Figure 2.

\section{Vegetation indices}

Landsat DN data were used to calculate six types of VIs, which have been shown to be effective in detecting forest changes and in monitoring of forest mortality (Collins \& Woodcock 1996, Vogelmann et al. 2009). VIs emphasise differences in the spectral response

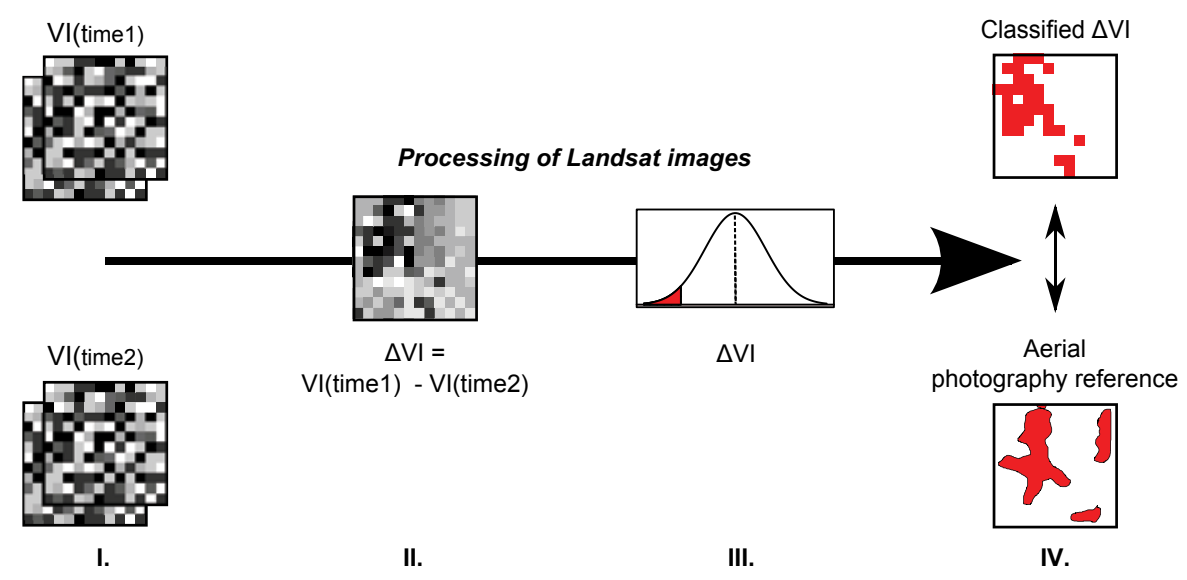

Figure 2 Schematic of the methodological approach. I. Calculation of Vegetation Indices (VI) for single years. II. Vegetation Index differencing resulting in the Changed Vegetation Index ( $\Delta$ VI). III. Classification of $\Delta$ VI by a set of threshold values. IV. Comparison between the classified $\Delta$ VI and reference aerial photography, leading to the calculation of the kappa statistic and ROC curves 
of different features, and reduce the impacts of topographic effects and illumination ( $\mathrm{Lu}$ et al. 2004). The VIs used in this study can be first divided into two groups. The first group of indices belongs to the family of ratio-based vegetation indices, while the second group is derived using orthogonal transformation techniques, such as Tasseled Cap transformation (Crist \& Cicone 1984). Applying map algebra, we created four types of ratio-based VIs: the Moisture Stress Index (MSI) or Band5/Band4 index, the Normalised Difference Moisture Index (NDMI), the Normalised Difference Vegetation Index (NDVI) and the Vegetation Condition Index (VCI) or Band7/Band4 index (Table 2). NDMI is comparable with the time Tasseled Cap wetness series in detecting forest disturbances (Jin \& Sader 2005). Using a combination of derived components from the Tasseled Cap transformation (namely brightness, greenness and wetness), we calculated the Disturbance Index (DI), which emphasises the contrast between the forest stand and bare soil (Healey et al. 2005, Masek 2005). The DI is based on the different spectral responses of stand-replacing disturbances, which have a higher reflectance of brightness and lower reflectance of greenness and wetness than do mature forests (Healey et al. 2006); Knorn et al. (2012) used this method succesfully in forest disturbance detection in the Carpathian Mountains. Because of the different behaviour of the greenness in our study, which was due to specific vegetation dynamics, we equally utilised the Modified DI ( $\left.D I^{\prime}\right)$ equation proposed by Hais et al. (2009).

\section{Normalisation}

All of the aforementioned indices calculated for the six examined years (2005-2009 and 2010-2011) were normalised on the area that was visually identified via aerial photography as being living forest in 2011 (the last year in the database). We have utilised the formula proposed by Healey et al. (2005):

$I_{r}=\frac{I-I_{\mu}}{I_{\sigma}}$

where $I r$ is an index value, $I \mu$ is the mean forest index of the undisturbed forest stand and $I \sigma$ is the SD of the forest index in the undisturbed area in the given year. The mean forest values and SDs were used only from stands that were unaffected by disturbances (such as harvesting or bark beetle outbreaks) over the entire period of the assessment. This type of rescaling helped to remove most of the influence of phenology or differences in sun-surface sensor geometries, and was related to a standard spruce stand in the same area in every year (Hais et al. 2009). A low-pass mean filter $(3 \times 3$ pixel window) was applied to the VI images to minimise the influence of any pixel misregistration.

Table 2 Landsat-derived spectral indices considered in the classification; bands (B) refer to the ETM band order

\begin{tabular}{llll}
\hline Index & Formula & Notes & Reference \\
\hline MSI & B5/B4 & Sensitive to conifer tree health & Vogelmann (1990) \\
NDMI & $(\mathrm{B} 4-\mathrm{B} 5) /(\mathrm{B} 4+\mathrm{B} 5)$ & Sensitive to green (healthy) vegetation & Jin \& Sader (2005) \\
NDVI & $(\mathrm{B} 4-\mathrm{B} 3) /(\mathrm{B} 4+\mathrm{B} 3)$ & Sensitive to biomass & Rouse et al. (1973) \\
VCI & B7/B4 & Sensitive to green (healthy) vegetation & Jakubauskas \& Price (1997) \\
DI & $\begin{array}{l}\text { DI = brightness } \\
\text { - (greenness + wetness) }\end{array}$ & $\begin{array}{l}\text { Emphasises the contrast between the } \\
\text { forest stand and bare soil }\end{array}$ & Healey et al. (2005) \\
DI' & $\begin{array}{l}\text { DI' = wetness } \\
\text { - brightness }\end{array}$ & $\begin{array}{l}\text { Modified DI, because of a different } \\
\text { behaviour of the greenness }\end{array}$ & Hais et al. (2009) \\
\hline
\end{tabular}




\section{Vegetation index differencing}

Detecting changes is one of the most common types of multi-temporal analysis; it involves the direct comparison of two images to identify how areas change over time. In this study, we used the approach of vegetation index (VI) differencing, following the procedures recommended by Singh (1989), to reveal changes in the forested area. VIs were calculated for every year. The resulting image of change is produced by subtracting the VI of the second year (after disturbance, time 2) from the first year (before disturbance, time 1) ( $\mathrm{Lu}$ et al. 2004). Hereafter, for images resulting from VI differencing, the term Changed VI $(\Delta V I)$ is applied. The last one was calculated at a $30 \times 30$ m pixel resolution:

$$
\Delta V I=V I(\text { time } 1)-V I(\text { time2) }
$$

\section{Classification of changed vegetation index}

Changed VIs $(\Delta$ VIs) were calculated for five two-year periods (2005-2006, 2006-2007, 2007-2008, 2008-2009 and 2010-2011). VI differencing equally reveals positive and negative changes in forest stands. Pixels revealing positive and negative changes are localised on different extremities of the $\Delta$ VI density plot (Figure 3). Because we focussed on forest stand degradation in this study, we neglected the potential changes caused by improved forest conditions. Hence, we considered only one extremity of the density plot as being 'changed'. For $\triangle \mathrm{VI}$ : VCI, MSI and DI, the negative change is located on the left side of the density plot. For $\Delta$ VI: NDMI, NDVI and $\mathrm{DI}^{\prime}$, the negative changes are located on the right side (Figure 3). The extremities of the density plot were determined visually.

The identification of the correct threshold value for reclassifying the entire area into a truly changed or unchanged location is the crucial factor in the detection of changes in a forest. The threshold $(x)$ is defined as the mul- tiplication of the standard deviation (SD) by the mean value:

mean $\pm x \cdot$ standard deviation

Thereafter, the mean and SD were extracted for every $\Delta \mathrm{VI}$. The possible threshold values varied from a mean of $-3 \cdot S D$ to a mean of +3 - SD. Accordingly, we used sequence values from -3 to +3 , with 0.1 step sizes. In this way, 60 values were applied to the $\Delta \mathrm{VI}$ as thresholds separating real change from unchanged pixels.

\section{Reference data}

The Research Station at Tatra National Park provided visual interpretations of bark beetle patches and spreading, as assessed by aerial photography from 2006 to 2009 and in 2011. Aerial photography from 2010 was not available and thus has not been evaluated. Polygons of BBOs were rasterised into $30 \times 30 \mathrm{~m}$ resolutions and snapped to the Landsat mosaic from 2011. Forested areas in the evaluated years were not included in the aerial surveys of BBOs. As a result, the area of forest cover used as a reference dataset was created by a combination of a forest inventory dataset from 2006 (which characterised the abundance of Norway spruce in different forest compartments) and by the visual interpretation of aerial photography. Forest compartments with Norway spruce abundances $>50 \%$ were adjusted visually for every year; thus, areas of possible clear-cuts were eliminated. The final reference image for a single year is composed of rasterised areas of a BBO and of rasterised actual forest cover. The majority filter of $3 \times 3$ pixels was applied to remove isolated pixels and to eliminate the 'salt-and-pepper' appearance that is common for pixel-based digital classification results (Coppin \& Bauer 1994). 

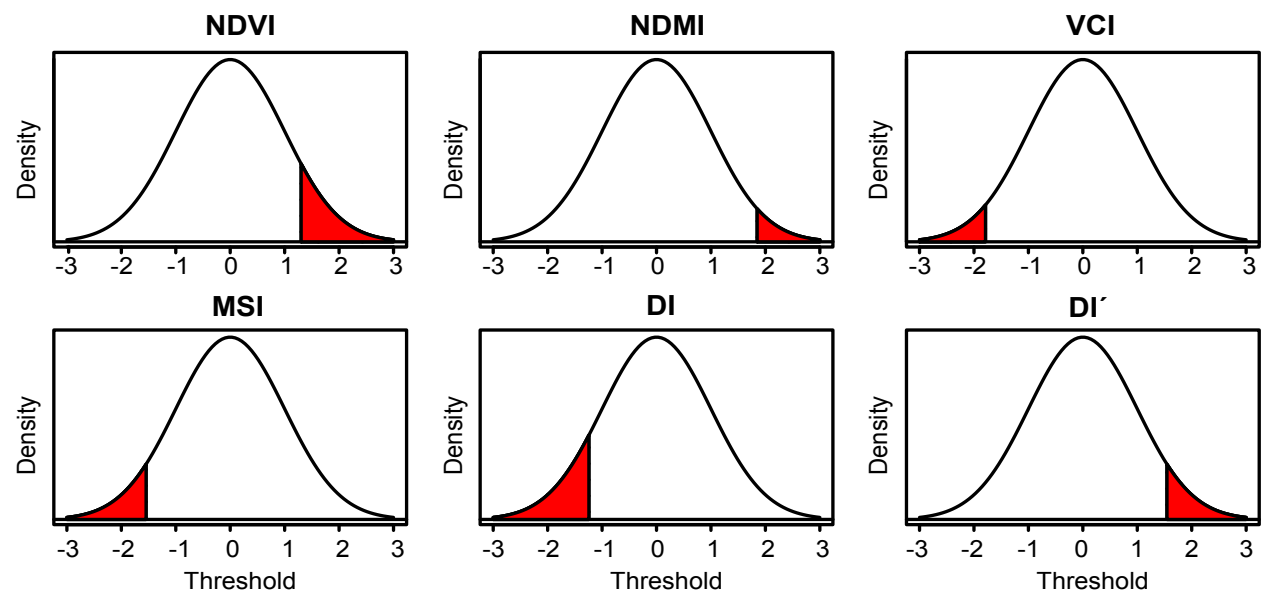

Figure 3 Density plot for Changed Vegetation Index $(\Delta \mathrm{VI})$ for selected Vegetation Indices (VIs: NDVI, NDMI, VCI, MSI, DI, DI'). Threshold value separating 'changed pixels' considered as BBOs (red) from 'unchanged pixels' (white) can be different for every VI. The decreasing vegetation quality because of BBOs is located on a different extremity of the $\Delta$ VI density plot

\section{Analysis of bark beetle infestation from aerial photography}

Areas of BBOs from aerial surveying were clumped into separate patches by Queen's case; thus, pixels connected by a pixel's angle were considered as one patch. The quantity and range of bark beetle patches was classed separately for every year. The severity of BBOs was characterised by the frequency of spots in five classes, depending on patch size: the first class was created by a bark beetle spot with an area of 1 pixel; the second class, up to 9 pixels, the third class was determined by an area up to 25 pixels, the fourth class, up to 49 pixels and the fifth class was formed by a spot's area over 49 connected pixels.

\section{Evaluation of classification}

Classified $\Delta$ VI was compared against rasterised reference dataset and cross-tabulated, producing a two-by-two confusion matrix (also called a 'contingency table', Table 3). The confusion matrix displays correctly classified pixels against incorrectly classified pixels where the classes are confusing. Two main metrics could be calculated: kappa statistics, as kappa index of agreement (Cohen 1960), and the metrics of receiver operating characteristics (ROCs) (Homayouni \& Roux 2004, Fawcett 2006).

Cohen's kappa coefficient is a statistical measure of inter-rater agreement for categorical items. The kappa reflects the difference between the actual agreement and the agreement expected by chance. The highest kappa index of agreement can identify the optimal threshold value to separate changed from unchanged pixels. The highest obtained kappa index values can provide the sensitivity of the index to detect BBOs.

ROCs can be used to visualise classifier performance in an ROC graph to select the proper threshold value: ROC curves compare the measures of pixels that are correctly and incorrectly classified as being BBOs. The probability of false positives (P[Fp]) operates with pixels classified as BBO. In the reference dataset, however, the same pixels are marked as forest; thus, they are false positives. The probability of true positives $(\mathrm{P}[\mathrm{Tp}])$ operates with pixels marked as $\mathrm{BBO}$ in both the $\Delta \mathrm{VI}$ and the refer- 
Table 3 Confusion matrix using ROC curves terminology. The probability of "true" or "false" bark beetle outbreak detections are calculated as: the probability of true positives, $\mathrm{P}(\mathrm{Tp})=\mathrm{Tp} /(\mathrm{Fn}+\mathrm{Tp})$, and the probability of false positives, $\mathrm{P}(\mathrm{Fp})=\mathrm{Fp} /(\mathrm{Tn}+\mathrm{Fp})$

\begin{tabular}{llll}
\hline & $\Delta$ VI Classification & \\
\cline { 3 - 4 } Reference & Forest & BBO \\
\hline & Forest & True negative (Tn) & False positive (Fp) \\
& BBO & False negative (Fn) & True positive (Tp) \\
\hline
\end{tabular}

ence dataset. In 2-dimensional ROC space, the $\mathrm{P}(\mathrm{Tp})$ (y axis) is displayed against the $\mathrm{P}(\mathrm{Fp})$ (x axis), thereby creating the ROC space.

Discrete classification produces only one point in an ROC space. As the best suitable threshold value, we considered that the point in ROC space with the minimal Euclidean distance from the optimal threshold point, where $\mathrm{P}(\mathrm{Fp})=0, \mathrm{P}(\mathrm{Tp})=1$, to represent the perfect classification. The ROC plot was displayed and the Euclidean distance was calculated for every contingency table. The shortest Euclidean distance represents the best suitable threshold value (Bucha \& Stibig 2008).

All visualisations were done using ArcGIS 10.2.1 and Erdas Imagine 2013. All calculations were performed using the raster (Hijmans 2014) and asbio (Aho 2014) packages in R statistical software (R Core Team 2014).

\section{Results}

\section{Kappa index of agreement}

The threshold values identified by the kappa statistics seemed to be more rigorous in detecting BBOs because fewer numbers of pixels were classified as BBOs (for example, threshold mean $-0.6 \cdot \mathrm{SD}$ and mean $-0.2 \cdot \mathrm{SD}$ for MSI in 2007 , as determined by kappa statistics and ROC, respectively). Following the kappa index values (Figure 4), the results were separated into two groups: years with high accuracy measures (2007 and 2011, kappa index $>70 \%$ and $>40 \%$, respectively) and a group of years with low accuracy measures (2006, 2008 and
2009, kappa index $\approx 10 \%$ ). In 2007 and 2011, VI differencing of MSI, VCI, NDMI, DI and DI' reached comparable kappa index values. Accordingly, we considered them to be the most appropriate to detect BBOs. The kappa index of NDVI, however, reached $35 \%$ and $36 \%$ in this time period. In hardly detectable years (2006, 2008 and 2009), NDVI reached the lowest value $(\approx 0 \%)$. For this reason, we do not recommend VI differencing of NDVI in further studies that identify BBOs as a vegetation change from one year to another. We applied a set of threshold values using the VI differencing method to separate changed from unchanged pixels. For visualisation, we selected threshold values and their adequate kappa indices for MSI (Figure 4) for the examined years, and the direct comparison of bark beetle patches identified by visual interpretation of infrared aerial photography (Figure 5a) and bark beetle outbreak by vegetation index differencing derived from Landsat imagery (Figure $5 \mathrm{~b}$ ). The best-suited threshold value was different from one year to another (Table 4). From the kappa statistics, the stable threshold value thus is not widely applicable to the detection of changes caused by BBOs.

\section{ROC curves}

In the graph of ROC space (i.e. for $\triangle \mathrm{MSI}$ in Figure 6a), the dependence between the proportion of pixels classified as true positives (Tp) and false positives (Fp) was evident. A combination of i) the highest probability of true positives $\mathrm{P}(\mathrm{Tp})$ and ii) the lowest probability of false negatives $\mathrm{P}(\mathrm{Fn})$ that yielded 


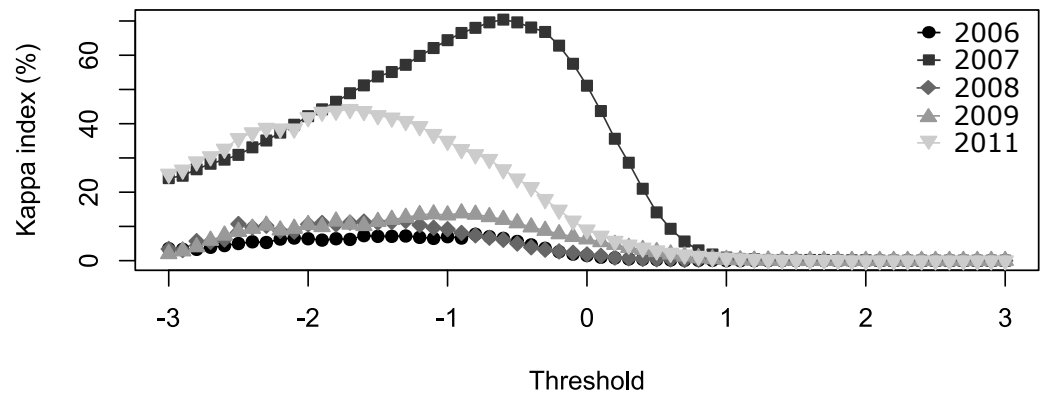

Figure 4 Kappa index of agreement with corresponding threshold values for $\Delta$ MSI for change identification for 2006-2009 and 2011. The highest kappa value identifies the best threshold value

(a)

(b)

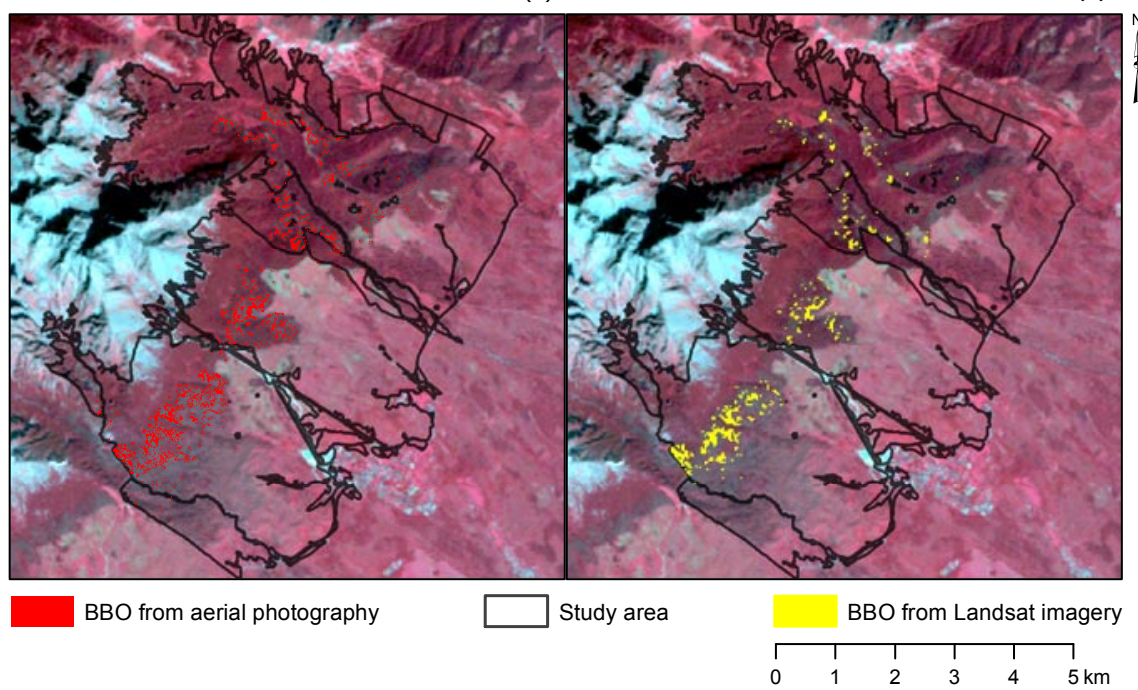

Figure 5 Comparison between bark beetle patches that originated in 2011 by visual interpretation of aerial photography (a) and by Vegetation Index differencing of Landsat imagery (b).

the lowest Euclidean distance from the $\mathrm{P}(\mathrm{Fp})=$ $0, \mathrm{P}(\mathrm{Tp})=1$ point indicating the best threshold value - and, equally, the most sensitive VI (Figure $6 \mathrm{~b}$ ) - was used to visualise the threshold values and associated Euclidean distance for $\Delta \mathrm{MSI}$. The lowest Euclidean distances for all years and VIs are shown in Table 4. In 2007, distances varied by $\approx 0.15$ for all VIs, except for the NDVI (Euclidean distance 0.49). Equally, in 2008, the NDVI was not appropriate to monitor changes caused by BBOs (Euclidean distance $\approx 1$ ). The lowest distances were in 2006, 2007 and 2011, which correspond to the results of the kappa statistics with the highest potential BBO detectability in 2007 and 2011. The most suitable indices from the ROC curves should be DI', MSI and VCI, with thresholds ranging from -0.4 to -0.2 for MSI and VCI and from 0.2-0.7 for DI'(Table 4).

\section{Analysis of bark beetle infestations from aerial photography}

The excellent results for the VI change detec- 
(a)

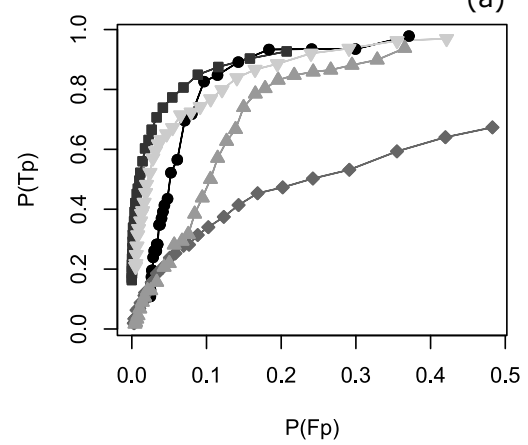

(b)

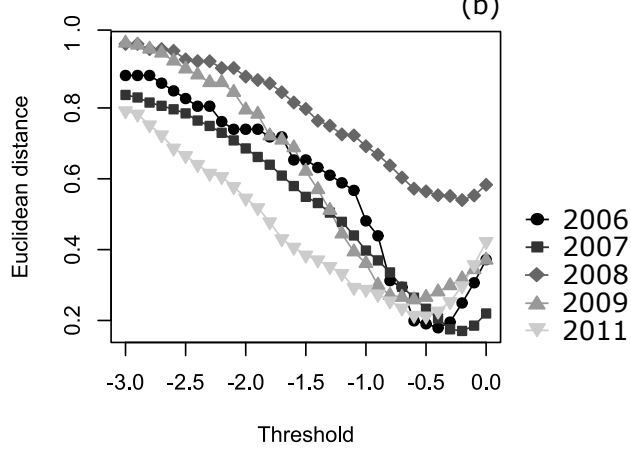

Figure 6 ROC curves and Euclidean distances obtained from different thresholds for $\triangle$ MSI for the examined years. (a) Probability of false positive (P[Fp]) versus true positive (P[Tp]) detection (ROC curves); (b) Euclidean distance from the point of the optimal solution ( $\mathrm{P}[\mathrm{Fp}]=0, \mathrm{P}[\mathrm{Tp}]=1)$. Threshold units: levels of standard deviation from the mean in $\triangle \mathrm{MSI}$

tion of the BBOs in 2007 and in 2011 may be due to the epidemic phase, which is characterised by large-sized patches of bark beetle spots (Figure 7). In 2007 and 2011, the recorded BBO was about 40 ha, compared with 4 ha, 18 ha and 15 ha in 2006, 2008 and 2009, respectively. Additionally, the proportion of pixels from small patches changed from one year to another. In the years before 2006 and during the epidemic phase (2008 and 2009) of BBOs, the spots of bark beetle infestation were smaller and more dispersed in forested areas. The strips in the Landsat ETM in 2008 limit the possibility of detecting newly created bark beetle patches. Applying image differencing, both the 2007-2008 and 2008-2009 periods were affected by this missing pixel data.

\section{Discussion}

\section{Vegetation indices}

All utilised VIs were previously marked as useful in monitoring declines in conifer forests (Vogelmann 1990; Ardö 1998; Meigs et al. 2011) because they capture subtle spectral changes of chlorophyl and carotenoid concentration of vegetation in decline in comparison to healthly leaf tissue (Rock et al. 1986). The NDVI seemed to be the most suitable index for monitoring forest biomass content (Myneni et al. 1995) and forest recovery (Mancino et al. 2013), but it should not be considered as an inverted value of forest decline. The method of VI differencing did not show good accuracy values when detecting forest changes caused by BBOs using NDVI (kappa values ranged from -0.2 to $36.4 \%$, Table 4 ). The most sensitive indices were the MSI, VCI and NDMI. VIs derived from Tasseled Cap transformations yielded equally high kappa values, and the DI' (Hais et al. 2009) is more appropriate for monitoring forest declines in the High Tatra Mountains than the DI (Healey et al. 2005).

Differences in the MSI, VCI, NDMI, DI and DI' are the most appropriate for monitoring BBOs, as they achieved good accuracy measures, mostly in the epidemic phases in 2007 and 2011. Low accuracy values were found in the incipient epidemic phase: all VIs had kappa values of $\approx 10 \%$. We do not recommend the the use of VI differencing of NDVI in the epidemic phase because of its poor classification accuracies. 
Table 4 The threshold values corresponding to the highest kappa values and to the lowest Euclidean distance value for the ROC curves for $\triangle \mathrm{VI}$ for the examined years and vegetation indices

\begin{tabular}{|c|c|c|c|c|c|}
\hline \multirow{2}{*}{ Year } & \multirow{2}{*}{$\Delta \mathrm{VI}$} & \multicolumn{2}{|l|}{ Kappa } & \multicolumn{2}{|c|}{ ROC curves } \\
\hline & & Threshold & Kappa & Threshold & Distance \\
\hline \multirow{6}{*}{ ¿̊̀ } & MSI & -0.8 & 7.4 & -0.4 & 0.18 \\
\hline & VCI & -0.7 & 8.6 & -0.4 & 0.19 \\
\hline & NDMI & 1.1 & 6.3 & 0.6 & 0.19 \\
\hline & NDVI & 1.7 & 6.5 & 0.3 & 0.43 \\
\hline & DI & -1.3 & 8.5 & -0.4 & 0.21 \\
\hline & $\mathrm{DI}^{\prime}$ & 1.6 & 9.4 & 0.7 & 0.16 \\
\hline \multirow{6}{*}{ ڤ్) } & MSI & -0.6 & 70.9 & -0.2 & 0.17 \\
\hline & VCI & -0.5 & 71.8 & -0.2 & 0.16 \\
\hline & NDMI & 0.8 & 70.9 & 0.3 & 0.18 \\
\hline & NDVI & 0.8 & 35.2 & 0.2 & 0.49 \\
\hline & DI & -0.6 & 72.7 & -0.3 & 0.15 \\
\hline & $\mathrm{DI}^{\prime}$ & 0.5 & 74.5 & 0.2 & 0.13 \\
\hline \multirow{6}{*}{ 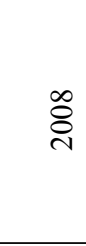 } & MSI & -1.6 & 11.8 & -0.2 & 0.54 \\
\hline & VCI & -1.6 & 9.7 & -0.4 & 0.62 \\
\hline & NDMI & 1.5 & 10.9 & 0.2 & 0.52 \\
\hline & NDVI & 3.0 & -0.2 & 3.0 & 1.00 \\
\hline & DI & -1.7 & 14.9 & -0.4 & 0.62 \\
\hline & $\mathrm{DI}^{\prime}$ & 1.9 & 17.3 & 0.2 & 0.53 \\
\hline \multirow{6}{*}{ \&े } & MSI & -0.9 & 14.0 & -0.6 & 0.26 \\
\hline & VCI & -0.7 & 12.1 & -0.6 & 0.27 \\
\hline & NDMI & 1.9 & 14.9 & 0.6 & 0.26 \\
\hline & NDVI & 0.9 & 8.0 & NA & NA \\
\hline & DI & -1.1 & 12.7 & -0.5 & 0.27 \\
\hline & $\mathrm{DI}^{\prime}$ & 1.1 & 11.9 & 0.5 & 0.31 \\
\hline \multirow{6}{*}{$\bar{\Xi}$} & MSI & -1.7 & 49.4 & -0.5 & 0.21 \\
\hline & VCI & -1.5 & 46.3 & -0.6 & 0.22 \\
\hline & NDMI & 1.7 & 49.3 & 0.5 & 0.23 \\
\hline & NDVI & 1.5 & 36.4 & 0.6 & 0.37 \\
\hline & DI & -1.8 & 43.9 & -0.7 & 0.21 \\
\hline & $\mathrm{DI}^{\prime}$ & 1.6 & 40.9 & 0.5 & 0.22 \\
\hline
\end{tabular}

\section{Applicability of stable thresholds}

The hypothesis that stable threshold values could be used to identify changes resulting from historical BBO mapping was not confirmed. The method of VI differencing and change identification by stable threshold values is not broadly applicable to identify forest changes because the threshold values in our study differed from one year to another. Therefore, it is impossible to apply the threshold on 306 the fixed level mean $\pm \mathrm{x} \cdot$ standard deviation using VI differencing without cross-tabulation to a reference dataset.

\section{Vegetation index differencing}

From the results, we can conclude that VI differencing is a very straightforward method to identify BBOs. This approach has two main disadvantages, however. The first is the necessity to determine the actual forest cover and to 
(a)

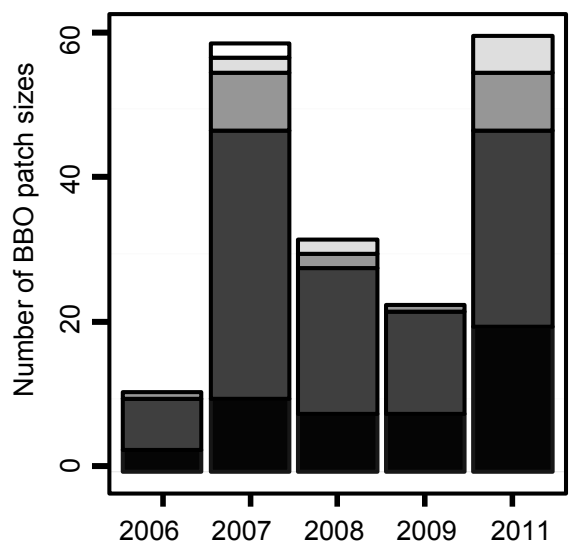

(b)

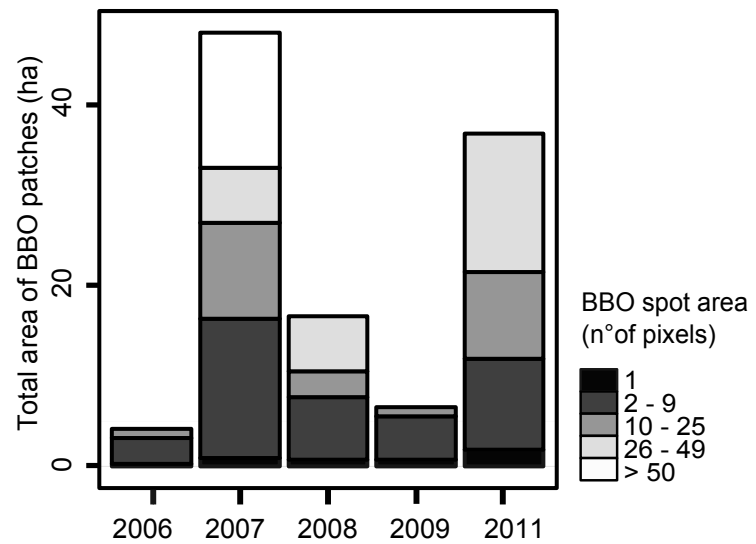

Figure 7 Bark beetle outbreak (BBO) patch sizes from a rasterised $\mathrm{BBO}$ survey derived from aerial photography for the examined years. Patches are classified into five classes depending on the number of pixels forming spots. (a) Quantity of patch sizes in different categories in the examined years; (b) total damaged area by BBO patches, classified into five classes depending on pixel size

constrict further analysis of vegetation change detection in the area. During the study, we tried to automatically identify forest cover by applying threshold values via visual inspection, using one of the Tasseled Cap components to describe surface brightness. This approach is useful for eliminating the darkest (lakes, steep slopes) and the brightest (rocks, buildings) objects in Landsat images (Meddens et al. 2013). Using normalisation based on unchanged forest for several years, however, as proposed by Healey (2005), it was impossible to determine the threshold values characterising the brightest objects and the darkest objects over the entire stack of Landsat images. Likewise, forest identification assumes the existence of a 'forest peak' or mode of the distribution if sufficient forest is present (Huang et al. 2008). This approach was not shown to be successful in simple forest identification. Forest peaks were mostly noticeable in Landsat bands 2, 3 and 5. After visual inspection, we found that the green band (B2) best separated forested and non-forested areas. The threshold position determined by the simple modal value masked areas of vegetation damage during BBOs, however. As a result, it was impossible to identify these areas using VI differencing. Forested areas were mapped for the second year of the change (time 2) in an attempt to eliminate the possibility of newly created clear-cuts.

The second problem is using $\Delta \mathrm{VI}$ to identify the cause of the change. Although the utilisation of a set of thresholds can be easily applicable, the need for a reference dataset remains. Equally, the preliminary knowledge of the actual phase of BBOs is required because, according to our results, VI differencing using selected vegetation indices is mostly appropriate during the epidemic phase of BBOs, which are characterised by a high expansion of spots and by a high proportion of continuous areas of damaged vegetation (Latifi et al. 2013).

If the BBO was in the incipient epidemic phase or post-epidemic phase, the spots were more dispersed and comprised small areas. It is more difficult to identify isolated patches of BBO. In small patches, the size of the infested patches is the decisive factor; thus, remotely sensed data that is of high to moderate spatial resolution is best-suited for detection (Wulder et al. 2006). The present study demonstrated 
the ability to detect and monitor BBOs using satellite imagery.

VI differencing is not widely applicable to monitoring annual BBOs without a reference dataset using a stable threshold value. In future studies, we recommend the utilisation of VIs derived from Landsat imagery simply by the application of map algebra (MSI, VCI and NDMI) to keep this approach more straightforward and easily interpretable. The determination of the forested area, however, remains the key factor in the identification of BBOs.

\section{Management implications}

Our study confirms the importance of aerial photography for the identification of trees attacked by bark beetles as part of forest management. Affordable Landsat imagery could possibly be used in the epidemic phase of extensive bark beetle outbreaks. Several suitable vegetation indices could be used (MSI, VCI and NDMI). It is possible that another type of satellite data with higher resolution could be used, as well, although price and availability could be limiting factors. Aerial photography remains the best available tool. The situation could be significantly changed after the launch of the new ESA satellite Sentinel-2 in 2015 (Drusch et al. 2012). The new satellite should carry sensors with sensors with significantly better spatial and spectral resolution than Landsat. Acquired data should be available in a similar way as the Landsat data.

\section{Conclusions}

VI differencing is mostly applicable during the epidemic phase of BBO, which is characterised by groups of bark beetle-attacked trees over large areas. In the epidemic phase, we achieved good results (kappa 70\%, overall accuracy 94\%) regarding BBO identification from Landsat imagery converted to VIs. The best-identified years were the change between
2006 and 2007 and from 2010 to 2011 . Both of these periods were characterised by large-scale epidemic phases of BBOs. The most suitable VIs were MSI, VCI and NDMI derived from Tasseled Cap transformations. VI differencing is not widely applicable to monitoring annual, historical BBOs without a reference dataset using a stable threshold value.

\section{Acknowledgements}

We thank L. Nad'o for help with R programming, and M. Blaženec and P. Mezei for comments on an earlier draft. This work was supported by the Slovak Research and Development Agency (APVV-0297-12) and the Grant Agency of the Ministry of Education and the Slovak Academy of Sciences (VEGA 0-160-09).

\section{References}

Aho K., 2014. asbio: A collection of statistical tools for biologists. R package version 1.0-5.

Ardö J., 1998. Remote sensing of forest decline in the Czech Republic. PhD thesis, Department of Physical Geography, Lund University, Lund, Sweden, 47 p.

Bucha T., 1999. Classification of tree species composition in Slovakia from satelite images as a part of monitoring of forest ecosystem biodiversity. Acta Instituti Forestalis 9: 65-84.

Bucha T., Stibig H.J., 2008. Analysis of MODIS imagery for detection of clear cuts in the boreal forest in northwest Russia. Remote Sensing of Environment 112(5): 2416-2429. DOI: 10.1016/j.rse.2007.11.008.

Cohen J., 1960. A coefficient of agreement for nominal scales. Educational and Psychological Measurement 20(1): 37-46. DOI: 10.1177/001316446002000104.

Collins J.B., Woodcock C.E.,1996. An assessment of several linear change detection techniques for mapping forest mortality using multitemporal Landsat TM Data. Remote Sensing of Environment 77: 66-77. DOI: 10.1016/0034-4257(95)00233-2.

Coops N.C., Waring R.H., Wulder M.A., White J.C., 2009. Prediction and assesment of bark beete-induced mortality of lodgepole pine using estimates of stand vigor derived from remotely sensed data. Remote Sensing of Environment 113(5): 1058-1066.

Coppin P.R., Bauer M.E., 1994. Processing of multitemporal Landsat TM imagery to change features. IEEE 
Transactions on Geoscience and Remote Sensing 32(4): 918-927.

Crist E.P., Cicone R.C., 1984. A physically-based transformation of thematic mapper data-the TM tasseled cap. IEEE Transactions on Geoscience and Remote Sensing GE-221(3): 256-263.

Fawcett T., 2006. An introduction to ROC analysis. Pattern Recognition Letters 27(8): 861-874.

Drusch M., Del Bello U., Carlier S., Colin O., Fernandez V., Gascon F., Hoersch B., Isola C. Laberinti P., Martimort P., Meygret A., Spoto F., Sy O., Marchese F., Bargellini P., 2012. Sentinel-2: ESA's optical high-resolution mission for GMES operational services. Remote Sensing of Environment 120: 25-36. DOI: 10.1016/ j.rse.2011.11.026.

Goodwin N.R., Coops N.C., Wulder M.A., Gillanders S., Schroeder T.A., Nelson T., 2008. Estimation of insect infestation dynamics using a temporal sequence of Landsat data. Remote Sensing of Environment 112(9): 3680-3689. DOI: 10.1016/j.rse.2008.05.005.

Griffiths P., Kuemmerle T., Baumann M., Radeloff V.C., Abrudan I.V., Lieskovsky J., Munteanu C., Ostapowicz K., Hostert P., 2014. Forest disturbances, forest recovery, and changes in forest types across the Carpathian ecoregion from 1985 to 2010 based on Landsat image composites. Remote Sensing of Environment 151, 72 88. DOI: 10.1016/j.rse. 2013.04.022.

Hais M., Jonášová M., Langhammer J., Kučera T., 2009. Comparison of two types of forest disturbance using multitemporal Landsat TM/ETM+ imagery and field vegetation data. Remote Sensing of Environment 113(4): 835-845. DOI: 10.1016/j.rse.2008.12.012.

Healey S.P., Cohen W.B., Zhigiang Y., Krankina O.N., 2005. Comparison of tasseled Cap-based Landsat data structures for use in forest disturbance detection. Remote Sensing of Environment 97(3): 301-310. DOI: 10.1016/j.rse.2005.05.009.

Healey S.P., Zhigiang Y., Cohen W.B., Pierce D.J., 2006. Application of two regression-based methods to estimate the effects of partial harvest on forest structure using Landsat data. Remote Sensing of Environment 101(1): 115-126. DOI: 10.1016/j.rse.2005.12.006.

Hijmans R.J., 2014. raster: raster: Geographic data analysis and modeling. R package version 2.2-31.

Huang C., Song K., Kim S., Townshend J.R.G., Davis P., Masek J.G., Goward S.N., 2008. Use of a dark object concept and support vector machines to automate forest cover change analysis. Remote Sensing of Environment 112(3): 970-985. DOI: 10.1016/j.rse.2007.07.023.

Jakubauskas M.E., Price K.P., 1997. Empirical relationships between structural and spectral factors of Yellowstone Lodgepole Pine Forests. Photogrammetric Engineering \& Remote Sensing 63(1): 1375-1381.

Jakuš R., Grodzki W., Ježík M., Jachym M., 2003. Definition of spatial patterns of bark beetle Ips typographus (L.) Outbreak Spreading in Tatra Mountains (Central Europe), Using GIS. In: McManus M.L., Liebhold A.M. (eds.), Ecology, survey and management of forest insect,), 1-5 September 2002, Kraków, Poland. USDA Forest Northeastern Research Station, Delaware, pp. $25-32$.

Jensen J.R., 1986. Introductory digital image processing. A remote sensing perspective. Prentice-Hall, New Jersey, USA. 379 p.

Jin S., Sader S.A., 2005. Comparison of time series tasseled cap wetness and the normalized difference moisture index in detecting forest disturbances. Remote Sensing of Environment 94(3): 364-372. DOI: 10.1016/ j.rse.2004.10.012.

Kennedy R.E., Yang Z., Cohen W.B., 2010. Detecting trends in forest disturbance and recovery using yearly Landsat time series: 1. LandTrendr - Temporal segmentation algorithms. Remote Sensing of Environment 114(12): 2897-2910. DOI: 10.1016/j.rse. 2010.07.008.

Knorn J., Kuemmerle T., Radeloff V. C., Szabo A., Mindrescu M., Keeton W. S., Abrudan I., Griffiths P., Gancz V., Hostert P., 2012. Forest restitution and protected area effectiveness in post-socialist Romania. Biological Conservation: 146(1): 204-212. DOI: 10.1016/j.biocon. 2011.12.020.

Lapin M., Faško P., Melo M., Št’astný P., Tomlain J., 2002. Climatic regions. In: Hrnčiarová T. (ed.), Landscape Atlas of the Slovak Republic. Ministry of Environment of the Slovak Republic, Banská Bystrica, Slovakia, 94 p.

Latifi H., Schumann B., Kautz M., Dech S., 2013. Spatial characterization of bark beetle infestations by a multidate synergy of SPOT and Landsat imagery. Environmental Monitoring and Assessment 186(1): 441-56. DOI: $10.1007 / \mathrm{s} 10661-013-3389-7$.

Lefsky M.A., Cohen W.B., 2003. Selection of remotely sensed data. In: Wulder M.A., Franklin S.E. (eds.), Remote sensing of forest environments: Concepts and Case Studies. Kluwer Academic Publishers, Boston, USA, pp. 13-47. DOI: 10.1007/978-1-4615-0306-4_2.

Lu D., Mausel P., Brondízio E., Moran E., 2004. Change detection techniques. International Journal of Remote Sensing 25(12): 2365-2401. DOI: 10.1080/014311603 1000139863.

Mancino G., Nole A., Ripullone F., Ferrara A., 2013. Landsat TM imagery and NDVI differencing to detect vegetation change: assessing natural forest expansion in Basilicata, southern Italy. iForest - Biogeosciences and Forestry 7(2): 76-85. DOI: 10.3832/ifor0909-007.

Masek J.G., 2005. LEDAPS disturbance products: User ' s guide and algorithm description (v. 2 - August 2007). NASA, Greenbelt MD, USA, 7 p.

Meddens A.J.H., Hicke J.A., Vierling L.A., Hudak A.T., 2013. Evaluating methods to detect bark beetle-caused tree mortality using single-date and multi-date Landsat imagery. Remote Sensing of Environment 132: 49-58. DOI: 10.1016/j.rse.2013.01.002.

Meigs G.W., Kennedy R.E., Cohen W.B., 2011. A Landsat time series approach to characterize bark beetle and defoliator impacts on tree mortality and surface fuels in conifer forests. Remote Sensing of Environment 115(12): 3707-3718. DOI: 10.1016/j.rse.2011.09.009. 
Myneni R.B., Hall F.G., Selers P.J., Marshak A.L., 1995. The interpretation of spectral vegetation indexes. IEEE Transactions on Geoscience and Remote Sensing: 33(2): 481-486. DOI: 10.1109/36.377948.

Nikolov C., Konôpka B., Kajba M., Kunca A., Janský L., 2014. Post disaster forest management and bark beetle outbreak in the Tatra National Park, Slovakia. Mountain Research and Development 34(4): 326-335. DOI: 10.1659/MRD-JOURNAL-D-13-00017.1.

Olsson H., 1993. Regression functions for multitemporal relative calibration of thematic mapper data over boreal forest. Remote Sensing of Environment 46: 89-102. DOI: 10.1016/0034-4257(93)90034-U.

R Core Team, 2014. R: A language and environment for statistical computing. R Foundation for Statistical Computing, Vienna, Austria. URL http://www.R-project. org/.

Rock B.N., Vogelmann J.E., Williams D.L., Vogelmann A.F., Hoshizaki T., 1986. Remote detection of forest damage. BioScience 36(7): 439-445 DOI: $10.2307 / 1310339$.

Rouse J.W., Haas R.H., Deering D.W., Schell J.A., 1973. Monitoring the vernal advancement and retrogradation (greenwave effect) of natural vegetation. Goddar Space Fligh Center, Greenbelt, Maryland, USA. 87 p.

Schelhaas M.J., Nabuurs G.J., Schuck A., 2003. Natural disturbances in the European forests in the 19th and 20th centuries. Global Change Biology: 9: 1620-1633. DOI: 10.1046/j.1365-2486.2003.00684.x.

Singh A., 1989. Digital change detection techniques using remotely-sensed data. International Journal of Remote Sensing 10(6): 989-1003. DOI: 10.1080/0143116 8908903939.

Svoboda M., Fraver S., Janda P., Bače R., Zenáhlíková J., 2010. Natural development and regeneration of a Central European montane spruce forest. Forest Ecology and Management 260(5): 707-714. DOI: 10.1016/ j.foreco.2010.05.027.

Svoboda M., Janda P., Nagel T.A., Fraver S., Rejzek J.,
Bače J., 2012. Disturbance history of an old-growth sub-alpine Picea abies stand in the Bohemian Forest, Czech Republic. Journal of Vegetation Science 23(1): 86-97. DOI: 10.1111/j.1654-1103.2011.01329.x.

Vogelmann J.E., 1990. Comparison between two vegetation indices for measuring different types of forest damage in the north-eastern United States. International Journal of Remote Sensing 11(12): 2281-2297. DOI: $10.1080 / 01431169008955175$.

Vogelmann J.E., Tolk B., Zhu Z., 2009. Monitoring forest changes in the southwestern United States using multitemporal Landsat data. Remote Sensing of Environment 113(8): 1739-1748. DOI: 10.1016/j.rse.2009.04.014.

Vogelmann J.E., Xian G., Homer C., Tolk B., 2012. Monitoring gradual ecosystem change using Landsat time series analyses: Case studies in selected forest and rangeland ecosystems. Remote Sensing of Environment 122: 92-105. DOI: 10.1016/j.rse.2011.06.027.

Wulder M.A., Dymond C.C., White J.C., 2005. Remote sensing in the survey of mountain pine beetle impacts: Review and recommendations. Canadian Forest Service, Victoria, Canada. 67 p.

Wulder M.A., Dynomd C.C., White J.C., Leckie D.G., Caroll A.L., 2006. Surveying mountain pine beetle damage of forests: A review of remote sensing opportunities. Forest Ecology and Management 221(1-3): 27-41. DOI: 10.1016/j.foreco.2005.09.021.

Wulder M.A., Coops N.C., 2013. Make Earth observations open access. Nature 513: 30-31. DOI: 10.1038/513030a.

Xiaojun Y., Lo C.P., 2000. Relative radiometric normalization performance for change detection from multi-date satellite images. Photogrammetric Engineering \& Remote Sensing 10(6): 989-1003.

Zhu Z., Woodcock C.E., Olofsson P., 2012. Continuous monitoring of forest disturbance using all available Landsat imagery. Remote Sensing of Environment 122: 75-91. DOI: 10.1016/ j.rse.2011.10.030. 